\title{
Trabalho e Riscos de Adoecimento: Um Estudo entre Policiais Civis
}

\author{
Vânia Cristine Cavalcante Anchieta ${ }^{1}$ \\ Ana Lúcia Galinkin \\ Ana Magnólia Bezerra Mendes \\ Elaine Rabelo Neiva \\ Universidade de Brasilia
}

\begin{abstract}
RESUMO - Este estudo teve como objetivo avaliar a percepção que os policiais civis do DF têm sobre o seu contexto de trabalho, suas exigências, assim como as vivências e os problemas físicos, psicológicos e sociais causados pelo trabalho, procurando fazer inferências sobre as estratégias de mediação utilizadas para evitar o sofrimento e os riscos de adoecimento. Foi aplicado o Inventário do Trabalho e Riscos de Adoecimento (ITRA) em 160 policiais civis, homens e mulheres, recém empossados na Instituição (tempo médio de oito meses de ingresso na Instituição). Os resultados indicaram que, apesar de não ficarem evidentes danos graves à saúde do policial novato, há riscos de acontecerem falhas nas estratégias de mediação em relação a fatores que levam ao adoecimento.
\end{abstract}

Palavras-chave: policiais civis; adoecimento no trabalho; psicodinâmica do trabalho.

\section{Work and Risks of Illness: A Study among Policemen}

\begin{abstract}
The purpose of this study was to evaluate the perception of police officers in Brasilia regarding the context in which they work. Their demands and experiences, as well as physical, psychological and social disorders caused by their professional activities were analyzed. Inferences were made about mediation strategies used to prevent suffering and the risks of illnesses. The Inventory of Work and Illness Risks was answered by 160 police officers, both men and women, who recently joined the institution (average of eight months on the force). Results indicated that although serious damage to the health of new police officers was not evident, there are risks of flaws in mediation strategies regarding factors which lead to disorders.
\end{abstract}

Keywords: police officers; work-related disorders; psychodynamics of work.

O trabalho hoje é concebido como uma atividade que envolve o homem em todas suas dimensões, exercendo importante papel na construção da subjetividade humana, e como tal, um elemento constitutivo da saúde mental e coletiva. Segundo Bridges (1995) o trabalho, além de contribuir fortemente para a sobrevivência material dos indivíduos, organiza e estrutura a vida das pessoas dando-lhes uma identidade, proporcionando uma rede de relações e de contatos, estruturando seu tempo e construindo espaço na sociedade através de direitos e obrigações.

Como conseqüência dessa importância, muitos pesquisadores têm se dedicado a entender a relação entre o trabalho e a saúde do trabalhador, podendo ser citados Barreto (2006), Lima (2005), Costa (2005), Martinez e Paraguay (2003). Esses autores têm em comum o fato de considerar que, dependendo das pressões e das exigências às quais está submetido ao realizar sua atividade profissional e dos recursos psicológicos de que dispõe para enfrentar as adversidades, o trabalhador poderá vir a adoecer. Destacam que o trabalho tem um caráter constitutivo da identidade e da subjetividade do trabalhador. Nessa perspectiva, alguns autores que têm se interessado em entender o policial enquanto um trabalhador (Cruz, 1989; Nascimento, 1999; Tamayo, 2002; Anchieta \& Galinkin, 2005), relatam em seus estudos que esses profissionais experimentam vivências de sofrimento no exercício

1 Endereço para correspondência: SQSW 304, Bloco J, apt. 312 Sudoeste. Brasília, DF. CEP 70.673-410. Fone: (61)3344-6767/(61)9983-2758.

E-mail:v.anchieta@brturbo.com.br de sua profissão. O adoecimento dos policiais, em função da atividade que exercem, é decorrente, tanto de seu contato com a violência, quanto das distintas vivências relacionadas ao trabalho (Amador, Santorum, Cunha \& Braum, 2002; Souza \& Minayo, 2005; Minayo, Souza \& Constantino, 2007).

Como evidencia o levantamento da produção brasileira em saúde e trabalho feito por Mendes (2003), existe, ainda, pouco interesse em estudos sobre o policial. Essa carência pode ser reflexo de um ressentimento de origem que acabou por colocar a população e intelectuais em oposição aos agentes da segurança pública, o que foi potencializado nos períodos de ditadura militar no Brasil. A consideração da segurança pública como questão da construção democrática e objeto da ciência social, vem se consolidando apenas a partir dos anos 90. Na busca realizada por Mendes (2003), foi feito um recorte de 1950 até 2002 e nesse período foram encontradas 860 dissertações ou teses com os descritores "saúde do trabalhador", "higiene ocupacional", "ergonomia", "toxicologia", "saúde ocupacional", entre outros. Dos 860 trabalhos encontrados apenas cinco eram estudos referentes à saúde do policial. Percebe-se, a partir desses dados, que estudos que refletem a preocupação com a saúde do policial são recentes, raros e podem ser ampliados.

Na perspectiva de explorar a questão da saúde do policial, o presente estudo tem como referencial teórico a psicodinâmica do trabalho. A construção desta teoria teve início nos anos 1980, na França, com os estudos de Christophe Dejours sobre a saúde do trabalhador. Os estudiosos da psicodinâmica 
do trabalho têm se dedicado a entender as relações dinâmicas entre organização do trabalho e processos de subjetivação, que se manifestam nas vivências de prazer-sofrimento, nas estratégias de ação para mediar contradições da organização do trabalho, nas patologias sociais, na saúde e no adoecimento (Mendes, 2007). A teoria tem por referências os conceitos da ergonomia do trabalho, como trabalho prescrito e trabalho real, priorizando aspectos relacionados à organização do trabalho (como ritmo, jornada, hierarquia, responsabilidade, controle). Segundo essa autora as intervenções propostas se voltam para a coletividade de trabalho, e não indivíduos isoladamente, e para aspectos da organização do trabalho a que os indivíduos estão submetidos.

À luz da psicodinâmica do trabalho, o sofrimento pode ser enfrentado através de estratégias de mediação, conceitos centrais da teoria, que têm como objetivo evitar a desestruturação e as desordens mentais dos trabalhadores. Quando há transformação das vivências de sofrimento em vivências de prazer é chamada de mobilização subjetiva ou coletiva. Quando essa transformação não acontece e a finalidade das estratégias passa a ser proteger o ego contra dissonâncias cognitivas e afetos dolorosos, são chamadas de estratégias defensivas. A mobilização subjetiva é, segundo Dejours (2004), uma fonte de vivência de prazer no trabalho, um meio para lidar com o sofrimento. Implica a ressignificação do sofrimento que, segundo Mendes (2007), é o processo por meio do qual o trabalhador se engaja no trabalho, entra em contato com sua subjetividade, utiliza sua inteligência prática e o coletivo de trabalho para transformar as situações causadoras de sofrimento.

Considerando a importância desses pressupostos teóricos para se entender as vivências de policiais civis no exercício de sua profissão, o objetivo deste estudo, de caráter exploratório, é avaliar como os policiais percebem o seu contexto de trabalho, suas exigências, as vivências e os problemas físicos, psicológicos e sociais causados pelo trabalho, e estabelecer relações entre esses fatores e os riscos à saúde, verificando se esses trabalhadores se utilizam de estratégias de mediação para evitar o sofrimento e os riscos de adoecimento. Optou-se pela utilização de um instrumento quantitativo, o Inventário de Trabalho e Riscos de Adoecimento - ITRA, mesmo considerando-se que a psicodinâmica do trabalho prioriza uma "abordagem de natureza predominantemente qualitativa", como afirmam Mendes, Ferreira e Cruz (2007, p. 105). Entretanto, alguns estudos (Mendes, 1999; Mendes \& Tamayo, 2001; Tamayo, Pinheiro \& Trócoli, 2002; Cruz, 2002), já vêm sendo feitos com o uso de medidas psicométricas, revelando que as contribuições da psicometria também têm sido importantes para desvelar, de modo sistemático, os processos de subjetivação originados na organização do trabalho.

Para mapear a produção de estudos com o ITRA, apresentam-se algumas pesquisas, nas quais se utilizou o inventário, visando à fundamentação empírica deste trabalho. Os primeiros estudos utilizando este inventário foram realizados após 2003, quando da construção e validação da primeira versão desse instrumento e, por ser uma ferramenta nova, não existe uma vasta publicação com a sua utilização. O primeiro estudo foi realizado por Ferreira e Mendes (2003), que aplicaram o ITRA em uma amostra de 1916 auditores da previdência social. Outras pesquisas com a aplicação desse instrumento foram realizadas posteriormente, sendo uma com digitadores terceirizados de uma instituição bancária, (Rego, Vieira, Pereira \& Facas, 2007). Neste estudos os autores concluíram que a utilização do instrumento possibilitou verificar os riscos de adoecimento no trabalho, indicando que esses trabalhadores estão no limite do sofrimento e que as estratégias de mediação funcionam, permitindo evitar o sofrimento e buscar o prazer. Em pesquisa realizada com carteiros que trabalham com o manuseio e entrega de documentos, por Rossi, Calgaro e Melo (2007) concluiu-se que os profissionais enfrentam o sofrimento no trabalho por meio estratégias defensivas para se adequarem às exigências da organização prescrita e buscar o prazer o que, de certa forma, garantiria a saúde no trabalho.

Em outro estudo, com bancários de uma instituição financeira pública, realizado por Sousa, Ferreia, Castro-Silva e Martins (2007) diagnosticou-se que a saúde dos trabalhadores da organização pesquisada encontra-se em situação de alerta, através da identificação de fatores de riscos para a saúde e para a qualidade de vida desses trabalhadores, apontando como fator mais significativo a rigidez da organização do trabalho. Com líderes religiosos em organizações pentecostais, Silva (2007) chegou a conclusão de que mesmo com sua base espiritual constituinte, os líderes religiosos também vivenciam sofrimento, mas numa intensidade menor que trabalhadores de outras organizações sem essa orientação. De uma forma geral os estudos demonstram que os trabalhadores mencionados atuam em organizações com acentuada rigidez e sobrecarga de trabalho, mas que tem desenvolvido estratégias defensivas para se manterem em condições de exercer suas funções. Nesse mapeamento não se identificam estudos com policiais, justificando assim, esta pesquisa e a necessidade de ampliação do uso do ITRA em outras categorias profissionais. Deste modo, esses achados podem ser comparados com os encontrados nesta pesquisa e avançar no estabelecimento de princípios gerais para o modelo "Trabalho e Riscos de Adoecimento".

\section{Método}

\section{Participantes}

A presente pesquisa foi realizada com policiais recém-empossados na Polícia Civil do Distrito Federal/PCDF, pois se supõe que nos primeiros contatos com o trabalho e com a instituição as estratégias de mediação já começam a ser utilizadas. Responderam às questões do ITRA um total de 160 policiais sendo $95(59,4 \%)$ do sexo masculino e 65 $(40,6 \%)$ do sexo feminino.

Todos os participantes tinham nível superior de escolaridade, sendo que 34 (21,3\%) tinham pós-graduação. Dos 160 policiais, $114(71,3 \%)$ eram solteiros enquanto os outros 46 $(28,8 \%)$ eram casados. Por serem recém-empossados, todos os policiais tinham menos de 1 ano de ingresso na Polícia variando de 4 a 11 meses. O tempo médio de ingresso na Instituição, para essa amostra, foi de aproximadamente 8 meses. A idade dos policiais variou de 23 a 48 anos, sendo a idade média igual a $29,8(\mathrm{DP}=4,58)$ e a idade mediana igual a 28 anos. 


\section{Instrumento}

Para a realização da pesquisa foram usadas todas as escalas que compõem o ITRA - Inventário sobre Trabalho e Riscos de Adoecimento. Considera-se importante descrever conceitualmente o modelo "Trabalho e Riscos de Adoecimento" desenvolvido por Ferreira e Mendes (2003) e Mendes e Ferreira (2007), que referencia a construção do Inventário. Este tem sustentação em algumas dimensões da inter-relação trabalho e processo de subjetivação, o próprio contexto de trabalho e os efeitos que ele pode exercer no modo do trabalhador vivenciá-lo e, conseqüentemente, sobre sua saúde. Assim, tem por objetivo investigar o trabalho e os riscos de adoecimento por ele provocado em termos de representação do contexto de trabalho, exigências (físicas, cognitivas e afetivas), vivências e danos.

O ITRA é composto de quatro sub-escalas e 128 itens (afirmativos), e cada sub-escala é composta por aproximadamente 30 itens, sendo que os fatores possuem entre 9 a 12 itens

O inventário foi validado com uma amostra heterogênea de 5.437 trabalhadores de empresas públicas federais do DF, com uso da análise fatorial, método PAF, rotação oblimin e análise da confiabilidade dos fatores pelo alfa de cronbach (Mendes \& Ferreira, 2007). A primeira escala, denominada Escala de Avaliação do Contexto de Trabalho é composta por três fatores: organização do trabalho, condições de trabalho e relações socioprofissionais, com eigenvalues de 1,5, variância total de 38,46\%, KMO de 0,93 e cargas fatoriais acima de 0,30. Os alfas de cronbach foram acima de 0,75. Os itens são avaliados por meio de uma escala de freqüência de cinco pontos, com itens negativos, cujo escore fatorial é obtido por meio da média entre os itens. Sua análise deve ser feita a partir de três níveis que consideram o ponto médio e desvios-padrão em relação ao ponto médio. Essa classificação envolve os níveis grave (escore fatorial acima de 3,7), moderado ou crítico (escores entre 2,3 e 3,69 ) e positivo ou satisfatório (escore abaixo de 2,3).

A segunda escala, denominada Escala de Custo Humano do Trabalho é composta por três fatores: custo físico, custo cognitivo e custo afetivo, com eigenvalues acima de 2,0, variância total de $44,46 \%$, KMO de 0,91 e cargas fatoriais acima de 0,30. Os alfas de cronbach foram acima de 0,84. Os itens são avaliados por meio de uma escala de nível de exigência dos indicadores de custo humano do trabalho, de cinco pontos, com itens negativos, cujo escore fatorial é obtido por meio da média entre os itens. Sua análise deve ser feita a partir de três níveis que consideram o ponto médio e desvios-padrão em relação ao ponto médio. Essa classificação envolve os níveis grave (escore fatorial acima de 3,7), moderado ou crítico (escores entre 2,3 e 3,69) e positivo ou satisfatório (escore abaixo de 2,3).

A terceira escala, denominada Escala de Indicadores de Prazer e Sofrimento no Trabalho é composta por quatro fatores: realização profissional, liberdade de expressão, falta de reconhecimento e falta de liberdade de expressão, com eigenvalues de 1,5 , variância total de 59,80\%, KMO de 0,92 e cargas fatoriais acima de 0,30 . Os alfas de cronbach foram acima de 0,80 . É uma escala de sete pontos cujo objetivo é avaliar nos últimos seis meses, a ocorrência (uma vez, duas vezes, etc.) dos indicadores de prazer e sofrimento no trabalho. $\mathrm{O}$ escore fatorial também é obtido por meio da média entre os itens. Sua análise deve ser feita a partir de três níveis que consideram o ponto médio e desvios-padrão em relação ao ponto médio. A análise dos itens de prazer ocorre de forma oposta aos itens de sofrimento. Para os indicadores de prazer, essa classificação envolve os níveis de positivo, satisfatório (escore fatorial acima de 4,0), moderado ou crítico (escores entre 2,1 e 3,9 ) e avaliação para raramente, grave (escore abaixo de 2,0).

A quarta escala, denominada Escala de Avaliação de Danos Relacionados ao Trabalho é composta por três fatores: danos físicos, danos psicológicos e danos sociais, com eigenvalues de 1,5, variância total de 50,09\%, KMO de 0,95 e cargas fatoriais acima de 0,30 . Os alfas de cronbach foram acima de 0,88 . É uma escala de sete pontos cujo objetivo é avaliar nos últimos três meses, a ocorrência (uma vez, duas vezes, etc.) dos indicadores de danos provocados pelo trabalho. Sua análise deve ser feita a partir de quatro níveis que consideram o ponto médio e desvios-padrão em relação ao ponto médio. Para os indicadores de dano, essa classificação envolve os níveis de avaliação mais negativa (escore fatorial acima de 4,1), avaliação mais grave (entre 3,1 e 4,0), moderado ou crítico (escores entre 2,0 e 3,0) e avaliação mais positiva, suportável (escore abaixo de 1,9).

$\mathrm{O}$ inventário teve validação anterior para vários grupos ocupacionais, contudo, ele ainda não havia sido aplicado em policiais civis. Tendo em vista tal situação, foram realizadas novas análises fatoriais para confirmar se a estrutura fatorial se mantinha neste grupo ocupacional. Os resultados mostraram que todas as sub-escalas apresentaram índices que confirmam a estrutura fatorial indicada. Os dados das análises fatoriais estão na Tabela 1 .

\section{Procedimento de coleta de dados}

Previamente à coleta de dados, em conformidade com as normas de ética da Resolução 196/96 do CNS, um Termo de Consentimento Livre e Esclarecido foi utilizado para registro da anuência dos envolvidos no estudo.

Os dados da pesquisa foram coletados em dez delegacias de polícia civil do Distrito Federal (amostra por acessibilidade). Após as formalidades de apresentação, feitas aos chefes das Seções de Apoio Administrativo/SAA, foram entregues os questionários aos policiais recém integrados, informando-lhe dos objetivos da pesquisa e do caráter de sigilo das respostas. Os participantes foram informados, também, que sua participação não lhes causaria danos ou prejuízos de qualquer ordem e de seu direito à desistência caso não se sentissem à vontade para participar da pesquisa. Após a autorização dos delegados-chefes foram distribuídos, no total, 250 questionários e obteve-se resposta para 160.

\section{Procedimento de análise de dados}

Foram realizadas estatísticas descritivas para os fatores do ITRA para diagnosticar a situação de trabalho dos policiais analisados. A partir das médias, escores fatoriais, foi elabo- 
rada uma distribuição de freqüência dos casos em cada um dos níveis de classificação das sub-escalas apresentados no tópico de instrumentos. Além das estatísticas descritivas, foram realizadas análises de variância entre os grupos, das variáveis demográficas e os fatores do ITRA como variáveis dependentes. O procedimento de ANOVA foi utilizado para comparar os fatores de cada uma das escalas que compõem o ITRA.

\section{Resultados}

O inventário teve validação anterior para vários grupos ocupacionais, contudo, ele ainda não havia sido aplicado em policiais civis. Tendo em vista tal situação, foram realizadas novas análises fatoriais para confirmar se a estrutura fatorial se mantinha neste grupo ocupacional. Os resultados mostraram que todas as sub-escalas apresentaram índices que confirmam a estrutura fatorial indicada pela validação original, conforme indicado nos tópicos de descrição do instrumento. Os dados das análises fatoriais estão na Tabela 1 .

Os dados da Tabela 1 corroboram a manutenção das estruturas fatoriais das sub-escalas para a amostra de policiais civis. A fatorabilidade das matrizes para cada uma das sub-escalas, além da variância explicada para cada uma das sub-escalas apresentaram índices similares a amostra original de validação. No caso da variância explicada, os números estiveram acima de $46 \%$ e os índices do KMO foram superiores a 0,83 . O número de fatores extraídos nas sub-escalas é o mesmo e os itens que foram carregados nos fatores da validação original permaneceram nos fatores com cargas fatoriais acima de 0,30 . Os dados de consistência interna dos fatores (alfas de cronbach) estiveram acima de 0,75.

Os resultados descritivos são apresentados por meio de uma distribuição de freqüência que classifica cada um dos fatores de cada uma das sub-escalas em termos de índices de gravidade relacionados à situação de trabalho. Esses dados descrevem a situação atual de trabalho do grupo estudado. Tais classificações foram comparadas por sexo, estado civil e idade como mostra a Tabela 2 .

De maneira geral, todos os fatores das escalas Contexto de Trabalho e Custo Humano de trabalho foram avaliados como críticos. Apenas o fator relações Socioprofissionais da Escala de Contexto de trabalho foi avaliado como satisfatório para os policiais com menos de 28 anos. E o fator custo cognitivo da Escala Custo Humano de trabalho foi avaliado como grave por todos os policiais. As Escalas de Prazer e Sofrimento foram avaliadas como satisfatórias e Danos relacionados ao trabalho, como suportáveis.

As análises de variância foram realizadas para verificar se haviam diferenças de percepção dos fatores do instrumento quanto às categorias sexo, estado civil, idade. $\mathrm{O}$ procedimento de Análise de Variância (ANOVA) foi utilizado para comparar as médias dos fatores em cada uma das escalas do ITRA, conforme mostra a Tabela 3 .

Com relação ao sexo, houve diferença significativa no fator custo afetivo da Escala de Custo Humano do Trabalho. Neste fator, os homens e as mulheres diferem quanto às suas reações afetivas, sentimentais e de estados de humor, indicando que sexo é uma variável importante na avaliação do custo afetivo e que os homens apresentam maior custo afetivo no trabalho. Em média, os homens são mais críticos do que as mulheres com relação ao custo afetivo do trabalho. Os itens que compõe este fator que mais influenciaram nessa diferença foram ser obrigado a lidar com a agressividade dos outros, ser obrigado a elogiar as pessoas, ser bonzinho com os outros, transgredir valores éticos.

Para o estado civil, de acordo com os resultados da ANOVA, não foram encontradas diferenças significativas entre os casados e os solteiros. Em geral os casados e os solteiros têm as mesmas opiniões em relação ao contexto de trabalho, custo humano do trabalho, prazer ou sofrimento no trabalho e os danos relativos ao trabalho. Ao que parece, o estado civil não é uma variável importante, que interfira na avaliação dos sujeitos sobre as condições de trabalho.

Por meio da classificação dos respondentes em grupos em relação à idade obtiveram-se $81(50,6 \%)$ com idade menor que 28 anos, que é a idade mediana, e $79(49,4 \%)$ com idade maior que 28 anos, conforme mostra a Tabela 4.

Ao testar a diferença entre esses dois grupos de idade, a ANOVA mostrou que há diferença no fator relações socioprofissionais da escala de Avaliação do Contexto de Trabalho. Neste fator os respondentes com idade menor que 28 e aqueles com mais de 28 anos diferem quanto aos modos de gestão do trabalho, comunicação e interação profissional. A idade aparece como uma variável importante na avaliação deste fator, sendo que aqueles que apresentam mais idade são os que avaliam esses fatores como mais críticos. Em média, aqueles com mais de 28 anos são mais críticos do que aqueles com menos de 28 anos com relação às relações profissionais. Os itens que mais influenciaram nessa diferença foram os funcionários são excluídos das decisões, existem dificuldades na comunicação entre chefia e subordinado, falta apoio

Tabela 1. Dados das análises fatoriais do instrumento para a amostra

\begin{tabular}{|c|c|c|c|c|}
\hline Sub-escalas & 1 & 2 & 3 & 4 \\
\hline Índices KMO & 0,85 & 0,83 & 0,88 & 0,89 \\
\hline $\begin{array}{l}\text { Variância explicada } \\
\text { pelo instrumento }\end{array}$ & $47,3 \%$ & $46 \%$ & $62 \%$ & $57 \%$ \\
\hline Fatores & $\begin{array}{c}\text { Três fatores extraídos } \\
\text { com os mesmos itens, } \\
\text { com cargas fatoriais aci- } \\
\text { ma de } 0,30\end{array}$ & $\begin{array}{c}\text { Três fatores extraídos } \\
\text { com os mesmos itens, } \\
\text { com cargas fatoriais aci- } \\
\text { ma de } 0,30\end{array}$ & $\begin{array}{l}\text { Quatro fatores com car- } \\
\text { gas fatoriais acima de } .30 \\
\text { e com os mesmos itens }\end{array}$ & $\begin{array}{c}\text { Três fatores extraídos } \\
\text { com os mesmos itens, } \\
\text { com cargas fatoriais aci- } \\
\text { ma de } 0,30\end{array}$ \\
\hline Alfas de cronbach & 0,75 a 0,80 & 0,75 a 0,80 & 0,80 a 0,90 & 0,75 a 0,85 \\
\hline
\end{tabular}


Tabela 2. Resumo dos maiores percentuais segundo a classificação dos fatores

\begin{tabular}{|c|c|c|c|c|c|c|}
\hline & \multicolumn{2}{|c|}{ Sexo } & \multicolumn{2}{|c|}{ Estado Civil } & \multicolumn{2}{|c|}{ Idade } \\
\hline & Masculino & Feminino & Solteiro & Casado & $<=28$ anos & $>28$ anos \\
\hline Organização do Trabalho & $\begin{array}{l}87,4 \% \\
\text { (crítico) }\end{array}$ & $\begin{array}{c}80,0 \% \\
\text { (crítico) }\end{array}$ & $\begin{array}{c}84,2 \% \\
\text { (crítico) }\end{array}$ & $\begin{array}{l}84,8 \% \\
\text { (crítico) }\end{array}$ & $\begin{array}{c}82,7 \% \\
\text { (crítico) }\end{array}$ & $\begin{array}{l}86,1 \% \\
\text { (crítico) }\end{array}$ \\
\hline Relações Socioprofissionais & $\begin{array}{l}51,6 \% \\
\text { (crítico) }\end{array}$ & $\begin{array}{l}52,3 \% \\
\text { (crítico) }\end{array}$ & $\begin{array}{c}50,9 \% \\
\text { (crítico) }\end{array}$ & $\begin{array}{l}54,3 \% \\
\text { (crítico) }\end{array}$ & $\begin{array}{c}55,6 \% \\
\text { (satisfatório) }\end{array}$ & $\begin{array}{c}62,0 \% \\
\text { (crítico) }\end{array}$ \\
\hline Condições de Trabalho & $\begin{array}{l}58,9 \% \\
\text { (crítico) }\end{array}$ & $\begin{array}{l}52,3 \% \\
\text { (crítico) }\end{array}$ & $\begin{array}{c}53,5 \% \\
\text { (crítico) }\end{array}$ & $\begin{array}{c}63,0 \% \\
\text { (crítico) }\end{array}$ & $\begin{array}{l}56,8 \% \\
\text { (crítico) }\end{array}$ & $\begin{array}{l}55,7 \% \\
\text { (crítico) }\end{array}$ \\
\hline Custo Afetivo & $\begin{array}{c}85,3 \% \\
\text { (crítico) }\end{array}$ & $\begin{array}{l}73,8 \% \\
\text { (crítico) }\end{array}$ & $\begin{array}{l}78,1 \% \\
\text { (crítico) }\end{array}$ & $\begin{array}{l}87,0 \% \\
\text { (crítico) }\end{array}$ & $\begin{array}{c}85,2 \% \\
\text { (crítico) }\end{array}$ & $\begin{array}{l}75,9 \% \\
\text { (crítico) }\end{array}$ \\
\hline Custo Cognitivo & $\begin{array}{l}72,6 \% \\
\text { (grave) }\end{array}$ & $\begin{array}{l}52,3 \% \\
\text { (grave) }\end{array}$ & $\begin{array}{l}64,9 \% \\
\text { (grave) }\end{array}$ & $\begin{array}{l}63,0 \% \\
\text { (grave) }\end{array}$ & $\begin{array}{l}67,9 \% \\
\text { (grave) }\end{array}$ & $\begin{array}{l}60,8 \% \\
\text { (grave) }\end{array}$ \\
\hline Custo Físico & $\begin{array}{l}61,1 \% \\
\text { (crítico) }\end{array}$ & $\begin{array}{c}64,6 \% \\
\text { (crítico) }\end{array}$ & $\begin{array}{c}61,4 \% \\
\text { (crítico) }\end{array}$ & $\begin{array}{c}65,2 \% \\
\text { (crítico) }\end{array}$ & $\begin{array}{c}64,2 \% \\
\text { (crítico) }\end{array}$ & $\begin{array}{l}60,8 \% \\
\text { (crítico) }\end{array}$ \\
\hline Liberdade de Expressão & $\begin{array}{c}73,7 \% \\
\text { (satisfatório) }\end{array}$ & $\begin{array}{c}73,8 \% \\
\text { (satisfatório) }\end{array}$ & $\begin{array}{c}76,3 \% \\
\text { (satisfatório) }\end{array}$ & $\begin{array}{c}67,4 \% \\
\text { (satisfatório) }\end{array}$ & $\begin{array}{c}79,0 \% \\
\text { (satisfatório) }\end{array}$ & $\begin{array}{c}68,4 \% \\
\text { (satisfatório) }\end{array}$ \\
\hline Falta de Reconhecimento & $\begin{array}{c}76,8 \% \\
\text { (satisfatório) }\end{array}$ & $\begin{array}{c}78,5 \% \\
\text { (satisfatório) }\end{array}$ & $\begin{array}{c}75,4 \% \\
\text { (satisfatório) }\end{array}$ & $\begin{array}{c}82,6 \% \\
\text { (satisfatório) }\end{array}$ & $\begin{array}{c}80,2 \% \\
\text { (satisfatório) }\end{array}$ & $\begin{array}{c}74,7 \% \\
\text { (satisfatório) }\end{array}$ \\
\hline Realização Profissional & $\begin{array}{c}72,6 \% \\
\text { (satisfatório) }\end{array}$ & $\begin{array}{c}75,4 \% \\
\text { (satisfatório) }\end{array}$ & $\begin{array}{c}73,7 \% \\
\text { (satisfatório) }\end{array}$ & $\begin{array}{c}73,9 \% \\
\text { (satisfatório) }\end{array}$ & $\begin{array}{c}76,5 \% \\
\text { (satisfatório) }\end{array}$ & $\begin{array}{c}70,9 \% \\
\text { (satisfatório) }\end{array}$ \\
\hline Esgotamento Profissional & $\begin{array}{c}56,8 \% \\
\text { (satisfatório) }\end{array}$ & $\begin{array}{c}56,9 \% \\
\text { (satisfatório) }\end{array}$ & $\begin{array}{c}50,9 \% \\
\text { (satisfatório) }\end{array}$ & $\begin{array}{c}71,7 \% \\
\text { (satisfatório) }\end{array}$ & $\begin{array}{c}51,9 \% \\
\text { (satisfatório) }\end{array}$ & $\begin{array}{c}62,0 \% \\
\text { (satisfatório) }\end{array}$ \\
\hline Danos Físicos & $\begin{array}{c}72,6 \% \\
\text { (suportável) }\end{array}$ & $\begin{array}{c}60,0 \% \\
\text { (suportável) }\end{array}$ & $\begin{array}{c}65,8 \% \\
\text { (suportável) }\end{array}$ & $\begin{array}{c}71,7 \% \\
\text { (suportável) }\end{array}$ & $\begin{array}{c}64,2 \% \\
\text { (suportável) }\end{array}$ & $\begin{array}{c}70,9 \% \\
\text { (suportável) }\end{array}$ \\
\hline Danos Sociais & $\begin{array}{c}86,3 \% \\
\text { (suportável) }\end{array}$ & $\begin{array}{c}83,1 \% \\
\text { (suportável) }\end{array}$ & $\begin{array}{c}86,0 \% \\
\text { (suportável) }\end{array}$ & $\begin{array}{c}82,6 \% \\
\text { (suportável) }\end{array}$ & $\begin{array}{c}88,9 \% \\
\text { (suportável) }\end{array}$ & $\begin{array}{c}81,0 \% \\
\text { (suportável) }\end{array}$ \\
\hline Danos Psicológicos & $\begin{array}{c}91,6 \% \\
\text { (suportável) }\end{array}$ & $\begin{array}{c}86,2 \% \\
\text { (suportável) }\end{array}$ & $\begin{array}{c}87,7 \% \\
\text { (suportável) }\end{array}$ & $\begin{array}{c}93,5 \% \\
\text { (suportável) }\end{array}$ & $\begin{array}{c}95,1 \% \\
\text { (suportável) }\end{array}$ & $\begin{array}{c}83,5 \% \\
\text { (suportável) }\end{array}$ \\
\hline
\end{tabular}

das chefias para meu desenvolvimento profissional. Para os respondentes com mais de 28 anos há maior dificuldade na comunicação e na interação profissional.

Outro teste foi utilizado para confirmar a relação entre a variável idade e as respostas das sub-escalas, no caso, o coeficiente de correlação de Pearson. O coeficiente de correlação de Pearson foi utilizado por se tratarem de duas variáveis métricas (Hair, Anderson \& Tatham, 2005). Além disso, a ANOVA possui restrições ao seu uso quando há diferenças no número de casos entre os grupos (Tabachnick \& Fidel, 2000), o que ocorre nesta amostra.

Mostrou, ainda, significância na diferença entre liberdade de expressão, da Escala de indicadores de Prazer-sofrimento no Trabalho, e a idade $(\mathrm{r}=-0,18 ; \mathrm{p}=0,02)$. Ou seja, pelo valor de ' $r$ ' ser negativo quanto maior a idade menos crítica será a avaliação do respondente. Para os mais velhos os fatores de prazer relacionados à liberdade de expressão no trabalho citados acima, são menos freqüentes do que para os mais jovens.

\section{Discussão}

Os fatores da escala contexto de trabalho: organização, condições de trabalho e relações socioprofissionais, foram avaliados como críticos pela maioria dos participantes, ou seja, há uma possibilidade de adoecimento sinalizada pela avaliação dos profissionais. Eles indicam que a organização do trabalho, as condições e as relações socioprofissionais se encontram aquém do que deveriam estar ou de suas expectativas. Como são profissionais em início de carreira e a situação de trabalho já não parece atender a essas expectativas, poderá haver um agravamento e gerar sofrimento para eles, em longo prazo, caso não sejam trabalhadas estratégias de mediação que inibam o risco de adoecimento. No que diz respeito às relações socioprofissionais, apenas os mais jovens, idade menor que 28 anos, em sua maioria, avaliaram-nas como satisfatórias. Os mais velhos são mais críticos do que os mais novos em relação a esta questão. Talvez, os mais velhos ao entrarem para 
Tabela 3. Média, desvio-padrão e diferenças dos fatores de avaliação por sexo

\begin{tabular}{|c|c|c|c|c|c|c|c|c|c|c|}
\hline \multicolumn{8}{|c|}{ Gênero } & \multirow{2}{*}{\multicolumn{3}{|c|}{ ANOVA }} \\
\hline & \multicolumn{3}{|c|}{ Masculino } & \multicolumn{3}{|c|}{ Feminino } & \multirow[b]{2}{*}{$\begin{array}{l}\text { Grau de li- } \\
\text { berdade (en- } \\
\text { tre grupos) }\end{array}$} & & & \\
\hline & $\mathbf{n}$ & Média & $\begin{array}{l}\text { Desvio- } \\
\text {-padrão }\end{array}$ & $\mathbf{n}$ & Média & $\begin{array}{l}\text { Desvio- } \\
\text {-padrão }\end{array}$ & & $\begin{array}{l}\text { Grau de } \\
\text { liberdade } \\
\text { (intra gru- } \\
\text { pos) }\end{array}$ & $F$ & $p$ \\
\hline $\begin{array}{l}\text { Organização do } \\
\text { Trabalho }\end{array}$ & 95 & 3,25 & 0,43 & 65 & 3,21 & 0,50 & 1 & 158 & 0,25 & 0,621 \\
\hline $\begin{array}{l}\text { Relações Sociopro- } \\
\text { fissionais }\end{array}$ & 95 & 2,31 & 0,60 & 65 & 2,35 & 0,63 & 1 & 158 & 0,12 & 0,731 \\
\hline $\begin{array}{l}\text { Condições de Tra- } \\
\text { balho }\end{array}$ & 95 & 2,82 & 0,85 & 65 & 2,86 & 0,85 & 1 & 158 & 0,09 & 0,768 \\
\hline Custo Afetivo & 95 & 2,89 & 0,49 & 65 & 2,65 & 0,52 & 1 & 158 & 9,09 & 0,003 \\
\hline Custo Cognitivo & 95 & 4,00 & 0,68 & 65 & 3,82 & 0,64 & 1 & 158 & 2,72 & 0,101 \\
\hline Custo Físico & 95 & 2,72 & 0,67 & 65 & 2,58 & 0,64 & 1 & 158 & 1,79 & 0,183 \\
\hline $\begin{array}{l}\text { Liberdade de Ex- } \\
\text { pressão }\end{array}$ & 95 & 4,56 & 1,11 & 65 & 4,62 & 1,25 & 1 & 158 & 0,11 & 0,745 \\
\hline $\begin{array}{l}\text { Falta de Reconheci- } \\
\text { mento }\end{array}$ & 95 & 1,34 & 1,21 & 65 & 1,34 & 1,32 & 1 & 158 & 0,001 & 0,980 \\
\hline $\begin{array}{l}\text { Realização Profis- } \\
\text { sional }\end{array}$ & 95 & 4,68 & 1,08 & 65 & 4,67 & 1,29 & 1 & 158 & 0,006 & 0,940 \\
\hline $\begin{array}{l}\text { Esgotamento Profis- } \\
\text { sional }\end{array}$ & 95 & 2,00 & 1,28 & 65 & 2,02 & 1,46 & 1 & 158 & 0,01 & 0,915 \\
\hline Danos Físicos & 95 & 1,47 & 1,18 & 65 & 1,71 & 1,18 & 1 & 158 & 1,62 & 0,206 \\
\hline Danos Sociais & 95 & 0,90 & 0,98 & 65 & 0,94 & 1,06 & 1 & 158 & 0,09 & 0,770 \\
\hline Danos Psicológicos & 95 & 0,71 & 1,02 & 65 & 0,84 & 1,21 & 1 & 158 & 0,47 & 0,493 \\
\hline
\end{tabular}

Tabela 4. Média, desvio-padrão e diferenças dos fatores de avaliação por estado civil

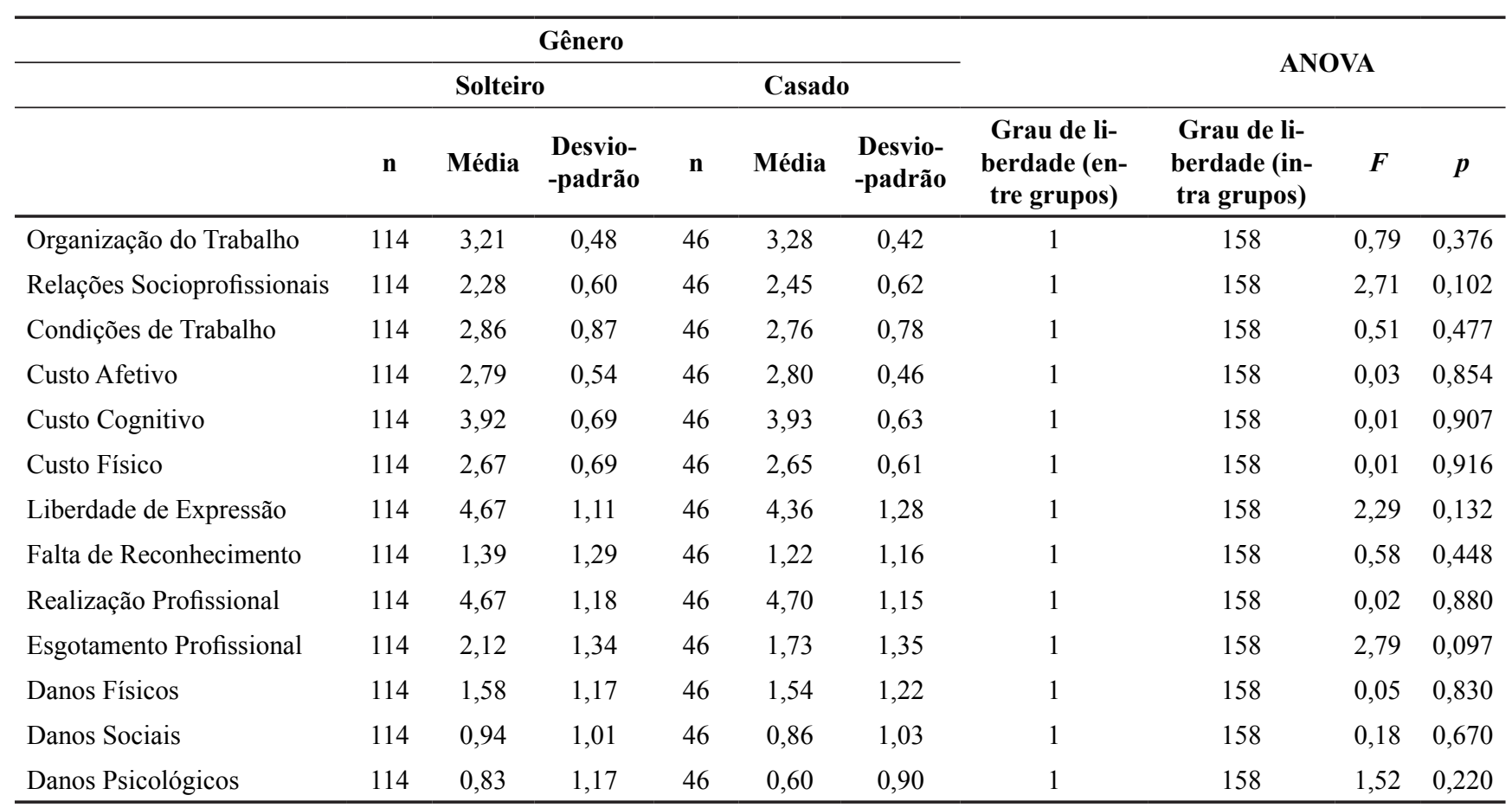


Tabela 5. Média, desvio-padrão e diferenças dos fatores de avaliação pela idade.

\begin{tabular}{|c|c|c|c|c|c|c|c|c|c|c|}
\hline \multicolumn{8}{|c|}{ Gênero } & \multirow{2}{*}{\multicolumn{3}{|c|}{ ANOVA }} \\
\hline & & $\begin{array}{l}\leq 28 \\
\text { (med }\end{array}$ & $\begin{array}{l}\text { anos } \\
\text { liana) }\end{array}$ & $\begin{array}{l}\geq 2 \\
\text { (me }\end{array}$ & $\begin{array}{l}\text { anos } \\
\text { liana) }\end{array}$ & & & & & \\
\hline & $\mathbf{n}$ & Média & $\begin{array}{l}\text { Desvio- } \\
\text {-padrão }\end{array}$ & Média & $\begin{array}{l}\text { Desvio- } \\
\text {-padrão }\end{array}$ & $\mathbf{n}$ & $\begin{array}{c}\text { Grau de li- } \\
\text { berdade (en- } \\
\text { tre grupos) }\end{array}$ & $\begin{array}{l}\text { Grau de li- } \\
\text { berdade (in- } \\
\text { tra grupos) }\end{array}$ & $\boldsymbol{F}$ & $p$ \\
\hline Organização do Trabalho & 81 & 3,24 & 0,48 & 3,22 & 0,45 & 79 & 1 & 158 & 0,07 & 0,797 \\
\hline Relações Socioprofissionais & 81 & 2,22 & 0,60 & 2,44 & 0,60 & 79 & 1 & 158 & 5,30 & 0,023 \\
\hline Condições de Trabalho & 81 & 2,79 & 0,82 & 2,88 & 0,87 & 79 & 1 & 158 & 0,46 & 0,500 \\
\hline Custo Afetivo & 81 & 2,79 & 0,50 & 2,80 & 0,54 & 79 & 1 & 158 & 0,03 & 0,875 \\
\hline Custo Cognitivo & 81 & 4,00 & 0,67 & 3,84 & 0,66 & 79 & 1 & 158 & 2,32 & 0,129 \\
\hline Custo Físico & 81 & 2,64 & 0,64 & 2,69 & 0,69 & 79 & 1 & 158 & 0,28 & 0,599 \\
\hline Liberdade de Expressão & 81 & 4,71 & 1,06 & 4,45 & 1,26 & 79 & 1 & 158 & 2,06 & 0,153 \\
\hline Falta de Reconhecimento & 81 & 1,23 & 1,15 & 1,45 & 1,34 & 79 & 1 & 158 & 1,20 & 0,276 \\
\hline Realização Profissional & 81 & 4,77 & 1,08 & 4,59 & 1,25 & 79 & 1 & 158 & 0,94 & 0,335 \\
\hline Esgotamento Profissional & 81 & 2,06 & 1,27 & 1,96 & 1,44 & 79 & 1 & 158 & 0,19 & 0,662 \\
\hline Danos Físicos & 81 & 1,56 & 1,14 & 1,58 & 1,23 & 79 & 1 & 158 & 0,01 & 0,925 \\
\hline Danos Sociais & 81 & 0,77 & 0,79 & 1,07 & 1,18 & 79 & 1 & 158 & 3,52 & 0,063 \\
\hline Danos Psicológicos & 81 & 0,65 & 0,88 & 0,88 & 1,29 & 79 & 1 & 158 & 1,72 & 0,192 \\
\hline
\end{tabular}

a instituição, já tragam experiências de trabalhos anteriores, o que favoreceria uma análise mais crítica com respeito ao novo ambiente de trabalho e às relações com colegas e chefias.

As exigências em relação ao trabalho, sinalizadas através do custo afetivo e do custo físico, foram avaliadas de forma crítica pela maioria dos sujeitos da pesquisa na análise descritiva, e o custo cognitivo foi avaliado como grave por todas as categorias - sexo, idade e estado civil. Portanto, a situação de trabalho desses profissionais tem exigido um alto custo cognitivo e algum grau de custos afetivo e físico, o que torna essa realidade de trabalho muito delicada e expõe o trabalhador a um custo humano relativamente alto, que pode gerar problemas em longo prazo.

Já na ANOVA houve diferença significativa no fator custo afetivo entre homens e mulheres, sendo maior entre os homens. Pode-se supor que os policiais sentem-se muito exigidos quando têm que resolver situações imprevistas durante uma abordagem de suspeitos ou criminosos na rua, ou mesmo na delegacia. Essas situações demandam dos policiais de ambos os sexos, capacidade de utilização do poder discricionário (Bandeira \& Costa, 2007) podendo haver dificuldades no entendimento desse "poder" que confronta-se com as imposições e limitações das atribuições, que não eram conhecidas antes do ingresso na instituição (Anchieta \& Galinkin, 2005). O fato dos homens se sentirem mais exigidos pode estar relacionado às expectativas culturais em relação à sua atuação no que diz respeito a iniciativa, comando e poder, como considera Ribeiro (2000) sobre a idéia do macho dominador.
O fato das mulheres demonstrarem ser menos críticas do que os homens em relação ao custo afetivo pode ser em função da utilização, por parte delas, de estratégias de mediação mais eficazes, pelo menos até este momento. Este dado pode ser mais explorado. Além disso, a própria instituição pode usar mecanismos que poupam as mulheres em função dos fatores culturais que envolvem a instituição. Paz, Galinkin e Neiva (2006) encontraram, em seu estudo, que mulheres no corpo de bombeiros têm duas alternativas, ou se tornam secretárias e podem usar de artifícios do papel social e sexual femininos, ou adotam posturas mais duras para suplantar os comportamentos discriminatórios dos homens na instituição. Caso a primeira situação ocorra com policiais civis, elas podem ser "poupadas" das situações mais difíceis do contexto de trabalho. São hipóteses que podem ser investigadas futuramente.

$\mathrm{Na}$ escala de Prazer e Sofrimento no Trabalho, todos os fatores foram analisados como satisfatórios pelos participantes. Para estes trabalhadores o prazer, avaliado pelos fatores reconhecimento e liberdade de expressão, prevalece sobre o sofrimento, que é avaliado pelos fatores esgotamento profissional e falta de reconhecimento. Apesar de criticar o contexto de trabalho, o policial novato na instituição revela sentir-se gratificado com a sua ocupação e parece ter orgulho do que faz. Ter mudado de trabalho, em busca de melhor remuneração e qualidade de vida, pode estar sustentando essa satisfação. A idealização de uma atividade heróica, que confere poder e prestígio, como constataram Anchieta e Galinkin (2007), pode, ainda, não ter sido confrontada com a realidade do trabalho, como acontece com os policiais mais 
antigos, como foi identificado em pesquisa realizada pelas mesmas autoras (Anchieta \& Galinkin, 2005).

Os danos, físicos, sociais e psicológicos, foram avaliados como suportáveis pela maioria dos trabalhadores, que é a avaliação mais positiva dos fatores. Com esses resultados pode-se inferir que as estratégias de mediação parecem estar presentes entre os policiais, uma vez que, mesmo avaliando o contexto de trabalho de forma crítica, ainda não fica evidenciado um número alto na escala de danos à saúde e nem sofrimento no trabalho. Uma nova avaliação do mesmo grupo após algum tempo, nessa nova função, poderá precisar melhor este fator. De qualquer forma, os fatores do Contexto de Trabalho sendo avaliados como críticos, em longo prazo, poderão significar possibilidade de adoecimento. Vale ressaltar que o percentual de afastamentos dos participantes da pesquisa para tratamento de saúde foi de nove policiais $(5,6 \%)$ que homologaram atestados de um a três vezes desde que ingressaram na instituição, sendo que, um deles tirou uma licença para acompanhamento de familiar, e outra foi indicação de repouso/gravidez, totalizando, então, sete $(4,37 \%)$ policiais que se afastaram para tratamento de saúde. Considerando a observação feita por Mendes e Ferreira (2007), de que nas estatísticas gerais $2 \%$ dos trabalhadores têm risco de adoecer, o que já deve ser considerado um número significativo em se tratando de vidas humanas, o percentual encontrado neste grupo pode ser um sinal de alerta.

Segundo Dejours (1992) o sofrimento no trabalho começa quando a relação homem-organização está bloqueada, quando o trabalhador usou todo o seu potencial de poder e de saber na organização do trabalho e depara-se com a impossibilidade de mudar a tarefa. Nesse sentido, os recursos ou defesas utilizados pelos sujeitos da pesquisa demonstram ainda estar sendo eficazes na situação atual. A consideração de que o prazer prevalece sobre o sofrimento pode estar se manifestando em decorrência da novidade da ocupação e das expectativas positivas no início de carreira em relação ao trabalho.

Considerando os resultados aqui encontrados com os das outras pesquisas citadas anteriormente, que utilizaram o mesmo instrumento, inferiu-se que há a utilização de estratégias de mediação em todas as categorias profissionais. A saúde dos carteiros (Rossi, Calgaro \& Melo, 2007) encontra-se em situação crítica e a dos bancários, em situação de alerta. Os dados demográficos entre os digitadores (Rego, Vieira, Pereira \& Facas, 2007) mostraram que os primeiros dez anos no cargo são os que mais trazem sensação de liberdade e realização profissional, e que a liberdade diminui com o passar dos anos no mesmo cargo. Entre os policiais novatos também foi possível observar satisfação com o trabalho. Em relação aos bancários (Souza, Ferreia, \& Castro-Silva, 2007), ficou constatado maior falta de apoio, entre os mais antigos, nas relações socioprofissionais, dado que ainda não pode ser comparado com os policiais, por serem novatos. $\mathrm{O}$ esgotamento profissional é maior em bancários mais jovens, com menos tempo de serviço. Esse último dado não apareceu na pesquisa com policiais novatos e os demais poderão ser avaliados em pesquisas futuras, com o mesmo grupo de policiais, para uma comparação dos resultados.

Os resultados indicam que, apesar de não terem ficado evidenciados danos graves à saúde do policial, é recomendá- vel verificar o que está ocorrendo na organização do trabalho, avaliada como crítica, para não haver riscos de acontecerem falhas nas estratégias de mediação, falhas estas que podem levar ao adoecimento. Estratégias de mediação individual e coletiva, conforme Mendes e Ferreira (2007), objetivam atender à diversidade das contradições presentes no contexto de produção. Neste estudo não foi possível identificar quais as estratégias utilizadas, mas inferiram-se, pelos resultados, que elas podem estar presentes, ainda que os danos não tenham se apresentado de forma grave.

A aplicação desta metodologia - escalas do ITRA foi importante para se ter uma idéia das representações compartilhadas pela maioria dos trabalhadores deste grupo em estudo, fornecendo bases para atingir-se os objetivos deste trabalho: avaliar como o policial percebe o seu trabalho e se está exposto ao adoecimento, na perspectiva teórica da Psicodinâmica do trabalho. Pôde-se perceber, também, com este estudo, e que poderá ser útil para avançar no estabelecimento de princípios gerais para o modelo "Trabalho e Riscos de Adoecimento", uma das propostas desta pesquisa, a importância de realização de um estudo longitudinal com esse mesmo grupo. O objetivo será de avaliar se ocorrerão mudanças nos resultados no decurso de um determinado período, que possam configurar em sofrimento no trabalho, uma vez que se supõe que o estado de sofrimento ocorre no decorrer do exercício da profissão, como constatam os estudos feitos por Dejours e Jayet (1994), Ferreira e Mendes (2001), e Mendes, Costa e Barros (2003).

Além disso, para futuras pesquisas, percebeu-se a necessidade de se desvelar as estratégias de mediação utilizadas pelos policiais para desempenharem o seu papel, o que poderá contribuir para que se avance nos conhecimentos acerca do fenômeno prazer/sofrimento do policial no exercício de sua profissão. Para tanto, outras estratégias metodológicas poderão ser utilizadas, como entrevistas, abordagem comum na clínica do trabalho, para aprofundar a compreensão dos resultados aqui encontrados, uma vez que o ITRA "identifica o visível, mas não se sabe o que está por trás dele" (Mendes \& Ferreira, 2007, p. 125). Pode-se observar que a utilização do instrumento mostra-se útil por fornecer bases para a construção de hipóteses que poderão ser testadas com outros instrumentos

Observou-se, ainda, que a aplicação do ITRA, resguardadas as suas limitações, já apresentadas, pode ser importante em pesquisas acadêmicas na temática saúde e trabalho, bem como para pesquisadores com pretensões de desenvolver pesquisa diagnóstica em saúde, para a implantação de programas de prevenção de adoecimento, o que pode ser uma significativa contribuição para a psicologia do trabalho.

\section{Referências}

Amador, F. S., Santorum, K., Cunha, C. S., \& Braum, S. M. (2002). Por um programa preventivo em saúde mental do trabalhador na brigada militar. Psicologia: Ciência e Profissão, 22(3), 54-61. 
Anchieta, V. C. C., \& Galinkin, A. L. (2005). Policiais civis: representando a violência. Psicologia \& Sociedade. 17(1), 29-37.

Anchieta, V. C. C., \& Galinkin, A. L (2007). De herói a vilão: as representações sociais de policiais civis sobre sua profissão. [Resumo]. V Jornada Internacional e III Conferência Brasileira sobre Representações Sociais, Brasília, DF.

Bandeira, L., \& Costa, A. (2007). A deontologia e o controle da atividade policial. In A. Costa \& L. Bandeira (Eds.), $A$ segurança pública do Distrito Federal: práticas institucionais e dilemas culturais (pp. 37-59). Brasília: LGE.

Barreto, M. M. S. (2006). Violência, saúde e trabalho (uma jornada de humilhações). São Paulo: PUCSP.

Bridges, W. (1995). Um mundo sem empregos. São Paulo: MAKRON.

Costa, A. L. R. C. da (2005). As múltiplas formas de violência no trabalho de enfermagem: o cotidiano de trabalho no setor de emergência e urgência clínica em um hospital público (Tese de Doutorado não publicada). Universidade de São Paulo, Ribeirão Preto.

Cruz, R. M. (2002). Avaliação da carga mental de trabalho. In R. M. Cruz, J. C. Alchieri \& J. J. Sarda Jr. (Eds.), Avaliação e medidas psicológicas: produção do conhecimento e da intervenção profissional (pp. 183-199). São Paulo: Casa do Psicólogo.

Cruz, S. G. F. P. (1989). Herói ou bandido? Estudo sobre a produção de identidade em policiais militares (Dissertação de Mestrado não publicada). Universidade de São Paulo, São Paulo.

Dejours, C. (1992). A loucura do trabalho: estudo de trabalho. São Paulo: Cortez.

Dejours, C. (2004). Addendum da psicopatologia à psicodinâmica do trabalho. In S. Lancman \& L. I. Szenelwar (Eds.), Christophe Dejours da psicopatologia à psicodinâmica do trabalho (pp.47-104). Rio de Janeiro, Fiocruz, Brasília, Paralelo 15.

Dejours, C., \& Jayet, C. (1994). Psicopatologia do trabalho e organização real do trabalho em uma indústria de processo: metodologia aplicada a um caso. In C. Dejours, E. Abdoucheli \& C. Jayet (Eds), Psicodinâmica do Trabalho (pp. 67-118). São Paulo: Atlas.

Ferreira, M. C., \& Mendes, A. M. (2001). "Só de pensar em vir trabalhar, já fico de mau humor": atividade de atendimento ao público e prazer-sofrimento no trabalho. Estudos de Psicologia, 6(1), 93-107.

Ferreira, M. C., \& Mendes, A. M. (2003). Trabalho e riscos de adoecimento - o caso dos auditores fiscais da previdência social brasileira. Brasília: FENAFISP.

Hair, J. F., Anderson, R. E., Tatham, R. L., \& Black, W. C. (2005). Análise multivariada de dados ( $5^{\mathrm{a}}$ ed.). São Paulo: Bookman.

Lima, M. E. A. (2005). Transtornos mentais e trabalho: o problema do nexo causal. Revista de Administração da FEAD, 2(1), 73-80.

Martinez, M. C., \& Paraguay, A. I. B. B. (2003). Satisfação e saúde no trabalho, aspectos conceituais e metodológicos. Cadernos de Psicologia Social do Trabalho, 6, 59-78.

Mendes, A. M. (1999). Valores e vivências de prazer-sofrimento no contexto organizacional. Tese de Doutorado, Universidade de Brasília, Brasília.

Mendes, A. M., \& Tamayo, A. (2001). Valores e vivências de prazer-sofrimento no contexto organizacional. Psico - USF, 6(1), 39-46.
Mendes, A. M., Costa, V. P., \& Barros, P. C. da R (2003). Estratégias de enfrentamento psíquico no trabalho bancário. Estudos e Pesquisas em Psicologia, 3(1), 59-72.

Mendes, A. M., \& Ferreira, M. C., \& Cruz, R. M. (2007). Inventário sobre Trabalho e Riscos de Adoecimento - ITRA: Instrumento auxiliar de diagnóstico de indicadores críticos no trabalho. In A. M. Mendes (Ed.), Psicodinâmica do Trabalho: teoria, método e pesquisas (pp. 111-126). São Paulo: Casa do Psicólogo.

Mendes, A. M, Ferreira, M. C., \& Cruz, R. M. (2007). O diálogo psicodinâmica, ergonomia, psicometria. In A. M. Mendes. (Ed.), Psicodinâmica do Trabalho: teoria, método e pesquisas (pp. 89-110). São Paulo: Casa do Psicólogo.

Mendes, R. (2003). Produção científica brasileira sobre saúde e trabalho, publicada na forma de dissertações de mestrado e teses de doutorado, 1950-2002. Rev. Bras. Med. Trabalho, 1(2), 87-118.

Minayo, M. C., Souza, E. R., \& Constantino, P. (2007). Riscos percebidos e vitimização de policiais civis e militares na (in)segurança pública. Cadernos de Saúde Pública, 23(11), 2767-2779.

Nascimento, N. C. do (1999). Uma delegacia de polícia no Distrito Federal: da estrutura à comunidade (Dissertação de Mestrado não publicada). Universidade de Brasília, Brasília.

Paz, M. G. T, Galinkin, A. L., \& Neiva, E. R. Cultura organizacional: uma análise dos ritos e mitos em organizações públicas. Manuscrito não-publicado.

Rego, V. B., Vieira, A. P., Pereira, J. A. de S., \& Facas, E. P. (2007). O trabalho dos digitadores terceirizados de uma instituição bancária pública. In A. M. Mendes (Ed.), Psicodinâmica do Trabalho: teoria, método e pesquisas (pp. 303-324). São Paulo: Casa do Psicólogo.

Ribeiro, A. S. M. (2000). Macho, Adulto, Branco, Sempre no Comando? (Dissertação de Mestrado não publicada). Universidade de Brasília, Brasília.

Rossi, E., Z., Calgaro, J. C. C., \& Melo, V. S. de (2007). O trabalho dos carteiros no manuseio e na entrega de correspondências. In A. M. Mendes (Ed.), Psicodinâmica do Trabalho: teoria, método e pesquisas (pp. 325-343). São Paulo: Casa do Psicólogo.

Silva, R. R. da (2007). O trabalho de líderes religiosos em organizações protestantes neopentecostal e tradicional. In A. M. Mendes (Ed.), Psicodinâmica do Trabalho: teoria, método e pesquisas (pp. 283-301). São Paulo: Casa do Psicólogo.

Sousa, C. M. de, Ferreia, J. B., Castro-Silva, L., M., de, \& Martins, M. V. (2007). O trabalho dos bancários em instituição financeira pública. In A. M. Mendes (Ed.), Psicodinâmica do Trabalho: teoria, método e pesquisas (pp. 345-359). São Paulo: Casa do Psicólogo.

Souza, E. R. de \& Minayo, M. C. (2005). Policial, risco como profissão: morbimortalidade vinculada ao trabalho. Ciência \& Saúde Coletiva, 10(4), 207-226.

Tabachnick, B. G., \& Fidell, L. S. (2000). Using multivariate statistics ( $4^{\text {rd }}$ ed.). Northridge, CA: HarperCollins College.

Tamayo, M. R. (2002). Burnout: Relações com a afetividade negativa, o coping no trabalho e a percepção de suporte organizacional (Tese de Doutorado não publicada). Universidade de Brasília, Brasília. 
Tamayo, M. R, Pinheiro, F., \& Tróccoli, B.T. (2002). Exaustão emocional: relações com a percepção de suporte organizacional e com as estratégias de coping no trabalho. Estudos de Psicologia, 7(1), 37-46.
Recebido em 08.05.2009 Primeira decisão editorial em 08.12.2009 Versão final em 08.01.2010 Aceito em 01.02.2010

I CONGRESSO INTERNACIONAL DE SAÚDE MENTAL
REFLEXOES PARA UMA PRÁTICA FUNDAMENTADA NOS VALORES HUMANOS
Período: 18 de Maio - 20 Maio 2011
Local: Ourinhos, SP - BR
NCDA GLOBAL CAREER DEVELOPMENT CONFERENCE
"CELEBRATING OUR PAST: ACHIEVING OUR DREAMS"
Período: 30 Junho - 02 Julho 2011
Local: São Paulo, BR

